\title{
Tight coupling of particle size, number and composition in atmospheric cloud droplet activation
}

\author{
D. O. Topping ${ }^{1,2}$ and G. McFiggans ${ }^{2}$ \\ ${ }^{1}$ National Centre for Atmospheric Science, University of Manchester, Manchester, UK \\ ${ }^{2}$ Centre for Atmospheric Science, University of Manchester, Manchester, UK \\ Correspondence to: D. Topping (david.topping@manchester.ac.uk) \\ Received: 23 August 2011 - Published in Atmos. Chem. Phys. Discuss.: 9 September 2011 \\ Revised: 16 March 2012 - Accepted: 22 March 2012 - Published: 4 April 2012
}

\begin{abstract}
The substantial uncertainty in the indirect effect of aerosol particles on radiative forcing in large part arises from the influences of atmospheric aerosol particles on (i) the brightness of clouds, exerting significant shortwave cooling with no appreciable compensation in the long wave, and on (ii) their ability to precipitate, with implications for cloud cover and lifetime.

Predicting the ambient conditions at which aerosol particles may become cloud droplets is largely reliant on an equilibrium relationship derived by Köhler (1936). However, the theoretical basis of the relationship restricts its application to particles solely comprising involatile compounds and water, whereas a substantial fraction of particles in the real atmosphere will contain potentially thousands of semi-volatile organic compounds in addition to containing semi-volatile inorganic components such as ammonium nitrate.

We show that equilibration of atmospherically reasonable concentrations of organic compounds with a growing particle as the ambient humidity increases has potentially larger implications on cloud droplet formation than any other equilibrium compositional dependence, owing to inextricable linkage between the aerosol composition, a particles size and concentration under ambient conditions.

Whilst previous attempts to account for co-condensation of gases other than water vapour have been restricted to one inorganic condensate, our method demonstrates that accounting for the co-condensation of any number of organic compounds substantially decreases the saturation ratio of water vapour required for droplet activation. This effect is far greater than any other compositional dependence; more so even than the unphysical effect of surface tension reduction
\end{abstract}

in aqueous organic mixtures, ignoring differences in bulk and surface surfactant concentrations.

\section{Background}

Köhler (1936) related the equilibrium size and chemical composition of an aerosol particle to ambient relative humidity, or saturation ratio of water vapour:

$$
S_{\mathrm{w}}=P_{\mathrm{w}} / P_{\mathrm{wo}}=\mathrm{RH} / 100=a_{\mathrm{w}} \exp \left(\frac{2 v_{\mathrm{w}} \sigma_{\mathrm{ws}}}{R T r_{\mathrm{drop}}}\right)
$$

where RH is the ambient relative humidity $(\%), P_{\mathrm{w}}$ the partial pressure of water vapour and $P_{i \mathrm{o}}$ the pure component vapour pressure of water. $P_{\text {wo }}$ represents the the partial pressure of water above a flat single component system comprising only itself in a sub-cooled state. $a_{\mathrm{w}}$ is the water activity (dimensionless), $v_{\mathrm{w}}$ the partial molar volume of water $\left(\mathrm{m}^{3} \mathrm{~mol}^{-1}\right), \sigma_{\mathrm{ws}}$ the solution surface tension $\left(\mathrm{N} \mathrm{m}^{-1}\right), R$ is the ideal gas constant $\left(8.314 \mathrm{~J} \mathrm{~K}^{-1} \mathrm{~mol}^{-1}\right)$ and $r_{\text {drop }}$ the radius of the droplet $(\mathrm{m})$. The Raoult effect, captured by $a_{\mathrm{w}}$, accounts for the lowered saturation ratio of water vapour above the solution resulting from the presence of a solute. The Kelvin effect, represented by the exponential, accounts for the increase in the equilibrium saturation ratio of water vapour above a spherical droplet as a result of its size. Combined, the two effects result in the Köhler curve as illustrated in the inset of Fig. 1, with a critical point defined by the supersaturation and wet size beyond which the particle may be assumed to have activated into a droplet and will exhibit runaway growth. 
Most theoretical analyses do not appreciate that the Köhler equation was derived for a particle comprising a single involatile solute and water. Likewise, interpretation of measurements of aerosol hygroscopicity and cloud activation in instruments which expose particles to controlled relative humidity assumes that only water re-equilibrates between the gas and condensed phase and that the solute amount remains constant at all points on the Köhler curve. A notable exception has been the treatment of sparingly soluble material which would increase dissolved soluble mass with increasing RH (Shulman et al., 1996), the limiting case being dissolution of all material when sufficient water is available. An analytical solution of Köhler theory for two semi-volatile compounds (water and one soluble gas) has been derived using various assumptions in Kulmala et al. (1993). Use of this model suggested that co-equilibration of nitric acid significantly alters the cloud activation potential of aerosol particles compared with traditional Köhler theory (Laaksonen et al., 1998; Kokkola et al., 2003), indicating that it is important to consider any increase in soluble material (the effective particle "dry size") in a droplet as it activates in the presence of condensable vapours. These and other compositional effects are reviewed in McFiggans et al. (2006). The organic aerosol fraction comprises compounds widely varying in volatility (Cappa and Jimenez, 2010), and gas-particle partitioning is a key process in determining the evolving organic fraction of particulate material in an ambient mixture of organic vapours (Pankow, 1994; Donahue et al., 2010; Hallquist et al., 2009). With respect to gas-particle partitioning, ambient vapour pressures of atmospherically important compounds are likely to be $<0.1 \mathrm{~Pa}$ and, in many cases, orders of magnitude below 0.1 Pa (Barley and McFiggans, 2010) and those that have vapour pressures ranging from $10^{-8}$ to $1 \mathrm{~Pa}$ will behave as semi-volatile components, partitioning substantially between the gaseous and condensed phases. Until the current work, the effect of co-condensing vapours on cloud activation potential has not been reported for more than two co-condensing gases (Romakkaniemi et al., 2005), including depletion from the gas phase. However, gas phase oxidation mechanisms of ambient parent hydrocarbons predict the abundance of thousands of degradation products (Jenkin et al., 1997; Aumont et al., 2005), many of which will act as semi-volatile condensable vapours under ambient conditions. Using an iterative algorithm to solve the problem as posed in the Appendix A, we present calculations of droplet activation including co-equilibration of compounds predicted by such schemes. We further constrain predicted activation behaviour using measured distribution of ambient component volatility.

Figure 1 illustrates 3 bands of Köhler curves for $50 \mathrm{~nm}$ dry size particles, representing conditions that may be expected to prevail in the atmosphere. The hatched and solid grey shaded areas represent conventional Köhler theory, with and without the assumption of surface tension suppression respectively. To account for the influence of any surface active material we have assumed a constant value of $50 \mathrm{mNm}^{-1}$. Only in the presence of very particular molecules that dramatically reduce surface tension at low mole fractions could such a low surface tension prevail at the point of activation (it has been postulated that biosurfactants may exhibit such properties, with measured bulk surface tensions as low as $\sim 30 \mathrm{mN} \mathrm{m}^{-1}$; Ekström et al., 2010). However, it has been shown that such suppression would largely be offset by a reduction in the Raoult effect resulting from movement of surface active molecules from the bulk to the surface of the particle (Sorjamaa et al., 2004). This latter effect has been ignored here, such that the band of curves serves as a reference point for a widely and erroneously postulated extreme effect of surface active material, unphysically neglecting differences between its bulk and surface concentrations. In contrast, the cerise shaded area represents our adaption of Köhler theory capable of accounting for the cocondensation of an unlimited number of compounds (in this example we use 2727 compounds predicted from a gas-phase degradation mechanism; see Appendix A), including depletion from the gas phase and assuming the surface tension of the droplet to be that of pure water. To recap, both traditional Köhler curve areas are constructed assuming that the condensed amount of organic material remains the same at all RH, only the changing concentration of water effecting the solute and curvature effect on the equilibrium position. The initial dry size of the particle is the same in all cases $(50 \mathrm{~nm})$, the amount of condensed organic material at $0 \%$ $\mathrm{RH}$ used to define this size. Each area represents the range of behaviour on changing the properties of a core material (the upper bound using an insoluble organic compound with molecular weight of $320 \mathrm{~g} \mathrm{~mol}^{-1}$, the middle curve a soluble organic compound with molecular weight of $320 \mathrm{~g} \mathrm{~mol}^{-1}$, the lower bound $\left.\left(\mathrm{NH}_{4}\right)_{2} \mathrm{SO}_{4}\right)$. In each case, moving from the insoluble compound to $\left(\mathrm{NH}_{4}\right)_{2} \mathrm{SO}_{4}$ predictably decreases the critical supersaturation $\left(S_{\text {crit }}\right)$ of the particle. Allowing the co-equilibration of all semi-volatile compounds leads to a larger concentration of condensed organic material at each $\mathrm{RH}$, significantly increasing the amount of soluble material and hence the effective dry particle size, thereby substantially reducing the critical supersaturation. It should be emphasised here that the effects of non-ideality are explicitly considered in Fig. 1 and hence the "water affinity" of the condensing organic compounds is directly incorporated into the predictions.

The actual amount of soluble material condensing per particle will depend on the size distribution and number concentration. In this example, the multicoloured arrows indicate the direction the coloured areas would follow on increasing and decreasing the concentration of particles. The shape of the size distribution, concentration, volatility profile and amount of condensable material will dictate this final result, a solution of the condensation dynamics the focus of future work. 
To further illustrate that the predictions shown in Fig. 1 are atmospherically reasonable, the $S_{\text {crit }}$ of particles as a function of the dry size have been calculated for a number of particles whose compositions correspond to the volatility distributions reported in Cappa and Jimenez (2010) (illustrated in the inset to Fig. 2). Unlike Fig. 1 we have not accounted for non-ideality in the proceeding calculations, the volatility distributions providing only a binned relationship between saturation vapour pressures and total abundance. The uppermost solid dark blue line again represents conventional Köhler theory, assuming a surface tension equal to that of pure water $\left(\sim 72 \mathrm{mNm}^{-1}\right)$; in this case, it has been assumed the same semi-volatile soluble material is present at all RH as under dry conditions. In contrast, the coloured lines represent our new predictions of $S_{\text {crit }}$ allowing co-equilibration of all semi-volatiles on increasing $\mathrm{RH}$, for different volatility distributions presented by Cappa and Jimenez (2010). For reference, the $S_{\text {crit }}$ for $\mathrm{NaCl},\left(\mathrm{NH}_{4}\right)_{2} \mathrm{SO}_{4}$ are given by the blue and black dotted lines. The influence of temperature on the predictions is surprisingly small, as illustrated by the cerise band in Fig. 2 for the oxygenated semi-volatile fraction of Cappa and Jimenez (2010) (OOA) between $T=278.5$ to $298 \mathrm{~K}$ and discussed in the Appendix A.

It is clear that allowing semi-volatile components, at levels directly measured in the atmosphere, to equilibrate with a growing particle on activation will have a substantial impact on critical supersaturation of the particle. In Fig. 2, the "Total OA" representation has a predicted $S_{\text {crit }}$ lower than that for $\left(\mathrm{NH}_{4}\right)_{2} \mathrm{SO}_{4}$ and higher than $\mathrm{NaCl}$. The different semivolatile fractions span a broad range of predicted $S_{\text {crit val- }}$ ues, all lower than traditional Köhler theory, particles with a biomass burning volatility profile predicted to activate even more readily than $\mathrm{NaCl}$ particles. The ranges of predicted effects on droplet activation behaviour based on measured volatility distributions are therefore comparable with, if not greater than, those from oxygenated VOCs predicted from a near-explicit model of VOC degradation. The block arrows indicate the effect changing the particulate concentration would have on the amount of additional condensed soluble material per particle through co-condensation, thus critical saturation ratio.

In these simulations we have not solved equilibrium between different sized particles or accounted for the concentration of particles as a function of size. Nonetheless, following the previous studies of Kulmala et al. (1993), the results in Fig. 1 highlight the inherent limitations of using traditional Köhler theory in the presence of semi-volatile organic compounds, including the difficulties in determining single particle hygroscopicity through laboratory studies as discussed in the following section. This would suggest that size, number and composition remain inherently coupled whenever semi-volatile compounds are present at reasonable atmospheric concentrations. To assess the true potential effect on cloud activation, thus cloud droplet number concentrations, the condensation dynamics has to be solved with appropriate aerosol size distributions. This is the basis of ongoing investigation.

Reasons as to why these levels of "hygroscopicity" are not prescribed to organic aerosol are discussed in the following section.

\section{Discussion}

Assuming the validity of measurements of sub- and supersaturated water uptake of particles, Dusek et al. (2006) demonstrated observationally that compositional impact on droplet activation was second order to particle size. Many subsequent investigations have extended the findings to universally represent such compositional effects in the single hygroscopicity parameter (Kappa-Köhler [ $\kappa$-Köhler ]) introduced by Petters and Kreidenweis (2007), relating water uptake to broad compositional characteristics such as the fraction of organic material detected by the Aerosol Mass Spectrometer (AMS) at mass fragment, $m / z=44$ (Jimenez et al., 2009; Duplissy et al., 2011). Such investigations have universally relied upon measurements that control the RH of the ambient or laboratory-generated sample, but not the saturation ratio of any other semi-volatile component. It is assumed in such studies that the particles have equilibrated with the RH in the instrument (sub-saturated in hygroscopicity tandem differential mobility analyser (HTDMA) instruments (Swietlicki et al., 2008) and supersaturated in cloud condensation nucleus (CCN) counters (Roberts et al., 2005). Since there is no active control of the saturation ratio of other semi-volatile components, it might be expected that they are free to condense or evaporate towards their equilibrium concentrations in the measurement timescales of the instruments. There is no a priori reason that the timescales for equilibration or the saturation ratios of all components in the atmosphere are the same as those in instruments used to measure particle hygroscopicity. Under some conditions it is possible that hygroscopic growth and cloud activation in the atmosphere fortuitously proceed in a manner analogous to those same processes within the instruments designed to measure them. For example, dilution of discrete pollution plumes with cleaner air faster than VOCs are oxidised to lower volatility components may lead to reduced saturation ratio before the particles in the plume have a chance to activate into cloud droplets. However, under other conditions, instruments may give a poor indication of the behaviour in the atmosphere. Hygroscopic growth and cloud activation of particles in air masses with extensive continuous sources of semi-volatile vapours (such as over boreal or tropical rainforests or sprawling urbanised regions) are likely to be substantially impacted by their tendency towards coequilibration. The reliability of instruments to measure suband supersaturated hygroscopic growth in a manner that can be directly extrapolated to atmospheric conditions is clearly in question. Discrepancies between measured composition 


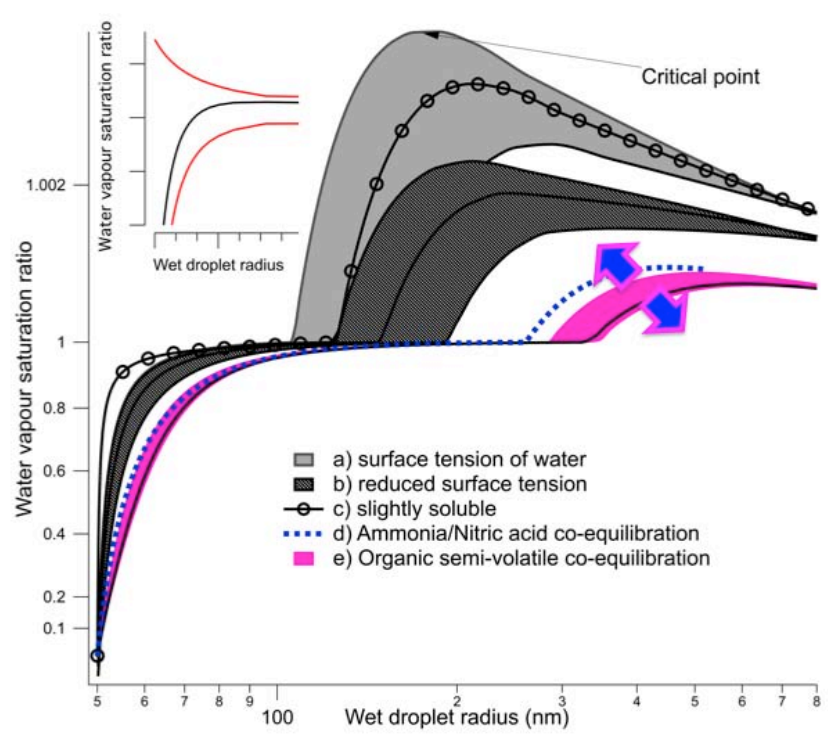

Fig. 1. Three representations of Köhler theory for a $50 \mathrm{~nm}$ dry particle, comparing traditional Köhler theory without (grey shaded area) and with (hatched surface area) an (unrealistically large) influence of surface active material assuming the surface active molecules do not reduce the Raoult effect, and our new formulation which allows the co-condensation of any number of compounds (coloured area). Above a saturation ratio of 1 the axis scale has been changed to more clearly display the critical point. Each area is constructed by changing the properties of a core (comprising $30 \%$ of the condensed mass at $0 \% \mathrm{RH}$ ) from insoluble organic compound with molecular weight of $320 \mathrm{~g} \mathrm{~mol}^{-1}$ to $\left(\mathrm{NH}_{4}\right)_{2} \mathrm{SO}_{4}$, with the solid line through each area representing a soluble compound with molecular weight of $320 \mathrm{~g} \mathrm{~mol}^{-1}$, (in each case, moving from the insoluble compound to $\left(\mathrm{NH}_{4}\right)_{2} \mathrm{SO}_{4}$ decreases the critical saturation ratio, $S_{\text {crit }}$ ). Circle markers represent the assumption of a slightly soluble shell using conventional Köhler theory. The dashed blue line represents co-equilibration of Ammonia and Nitric acid for brief comparison to the work of Kulmala et al. (1993). In this instance the equilibrium constants were taken from Seinfeld and Pandis (1998) and the core assumed to be $\left(\mathrm{NH}_{4}\right)_{2} \mathrm{SO}_{4}$ to obtain the lowest $S_{\text {crit }}$. Equilibration of multiple semi-volatile components results in by far the largest decrease in critical supersaturation and increase in cloud droplet forming behaviour, by increasing the soluble mass as the RH increases, towards activation. The actual amount of soluble material condensing per particle will depend on the size distribution and number concentration. As all simulations at $0 \% \mathrm{RH}$ correspond to a number concentration of $\sim 600 / \mathrm{cc}$ in this example, the multicolored arrows indicate the direction the coloured areas would follow on increasing and decreasing the concentration of particles. The shape of the size distribution, concentration, volatility profile and amount of condensable material will dictate this final result, a solution of the condensation dynamics the focus of future work. The small inset at the top left of the figure is a simple schematic displaying the contribution of the Raoult (bottom red line) and Kelvin terms (top red line) to the resulting Köhler curve (black line). The Kelvin term asymptotically approaches infinity as the size tends to zero.

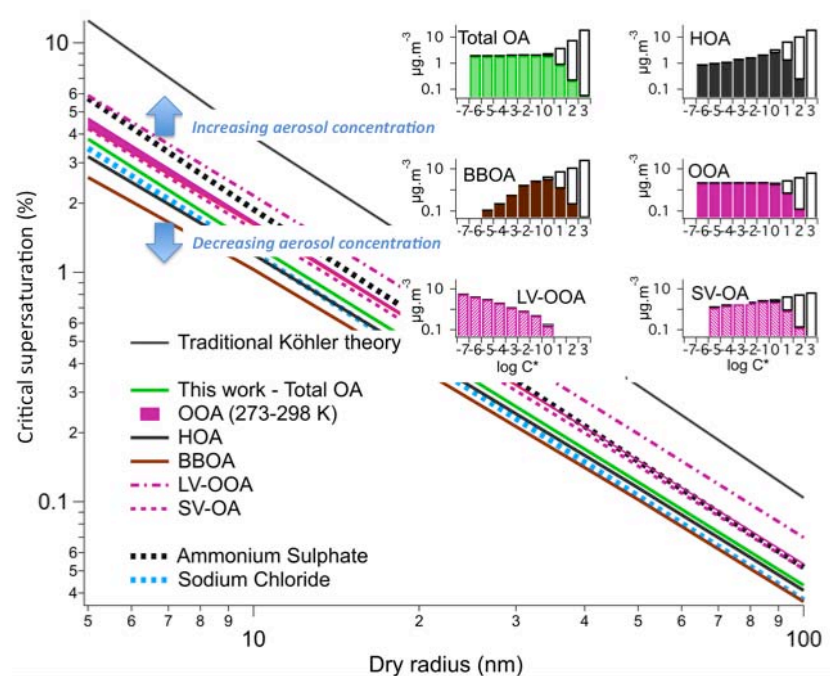

Fig. 2. Critical supersaturation as a function of dry particle radius $(\mathrm{nm})$ for multiple semi-volatile fractions taken from Cappa and Jimenez (2010), shown in the inset panel. "Total OA" represents the entire semi-volatile fraction, the "Traditional Köhler theory" lines representing traditional Köhler theory predictions for the same aerosol type. Additional representations are as follows: HOAHydrocarbon-like, OOA - Oxygenated, BBOA-Biomass burning, LV-OOA - Low volatility, SV-OOA - Semi-volatile organic aerosol. For reference the $S_{\text {crit }}$ for $\mathrm{NaCl},\left(\mathrm{NH}_{4}\right)_{2} \mathrm{SO}_{4}$ are given as blue and black dashed lines. The actual amount of soluble material condensing per particle will depend on the size distribution and number concentration. To demonstrate this, the solid blue arrows arrows indicate the direction the predicted critical saturation ratios, after accounting for co-condensation, would follow on increasing and decreasing the concentration of particles. The shape of the size distribution, concentration, volatility profile and amount of condensable material will dictate this final result, a solution of the condensation dynamics the focus of future work.

and predicted hygroscopic growth when particles contain substantial amounts of semi-volatile material show that correction for this fraction are required (Gysel et al., 2004) and discrepancies between measurements of sub-saturated hygroscopic growth and droplet activation in the laboratory (Good et al., 2010) and atmosphere (Good et al., 2010; Irwin et al., 2010) are likely attributable to this effect. One might imagine that good agreement will be achieved when attributing the contribution of hygroscopicity from individual measured components (derived from, say, a $\mathrm{CCN}$ counter) to a measured composition distribution and comparing the overall hygroscopicity to that measured in ambient air using the same instrument. It is less clear that good agreement will be achieved when individual component hygroscopicity derived from one instrument (e.g. CCN counter) is compared with ambient hygroscopicity measured by another (e.g. HTDMA). It is likely that, under some circumstance, reasonable agreement between instruments is attributable to kinetic mass transfer limitations to particles within the instruments 


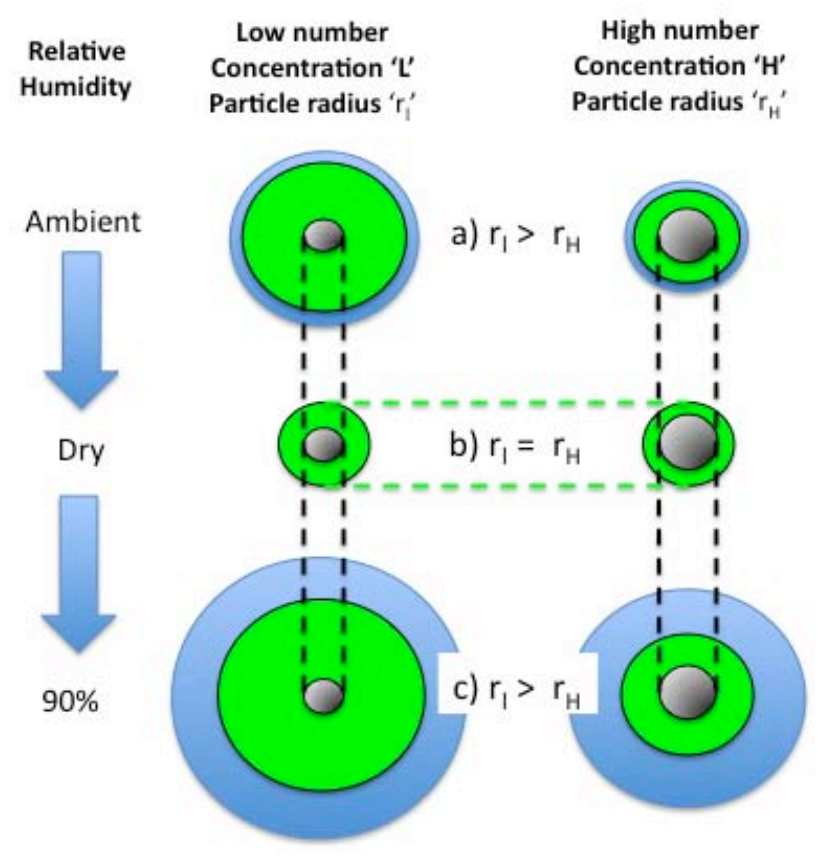

Fig. 3. Schematic showing the change in condensed organic material (green areas) on particles with an existing organic core (black areas) as a function of RH (left panel) and the effect on water uptake (blue areas) for a specific aerosol size and two separate number concentrations (the middle panel represents a low number concentration, the right a high concentration). The dry size for both populations, as measured by the instrument, are equal (the middle row).

which may or may not play a role in the ambient atmosphere owing to the different prevailing timescales, particularly given the recent identification of glassy solid particles (Virtanen et al., 2010) with associated retardation of diffusion (Tong et al., 2011). Further complication may be attributable to reduction in component volatility through condensed phase reactions (Camredon et al., 2010).

The dependence of partitioned mass per particle on number concentrations also has important implications for how the aerosol particle is perturbed in instruments measuring hygroscopicity. Take a hypothetical case study of two particle concentrations entering a HTDMA, with the same total available condensable material, as illustrated in Fig. 3. As the particles are dried, the drier will remove all of the water and an amount of organic material associated with the water that has been removed (point $b$ ). The size of the particle that would have been present under ambient conditions (point a) would be smaller under a high number concentration (case $\mathrm{H}$ ), compared to a low number concentration (case L), for the same total amount of condensable material because this semi-volatile material is shared between greater number concentrations. On humidifying both populations to $90 \% \mathrm{RH}$, the low number concentration particles (case L) will take up more mass per particle leading to higher growth fac-
Table 1. Kappa-Köhler [ $\kappa$-Köhler ] values calculated at $90 \% \mathrm{RH}$ $(\kappa$-HTDMA) and at the critical point $(\kappa-\mathrm{CCN})$ for multiple concentrations.

\begin{tabular}{lrrr}
\hline & $\begin{array}{r}6000 \mathrm{~cm}^{-3} \\
(\text { Case H) }\end{array}$ & $600 \mathrm{~cm}^{-3}$ & $\begin{array}{r}60 \mathrm{~cm}^{-3} \\
(\text { Case L) }\end{array}$ \\
\hline$\kappa$-HTDMA & 0.1073 & 0.3016 & 1.0527 \\
$\kappa$-CCN & 0.1102 & 0.8722 & $>5$ \\
\hline
\end{tabular}

tors. At even higher RH, such as in a CCN instrument, the non-linear addition of further condensed mass would theoretically lead to even higher growth factors. In Table $1 \kappa$-Köhler values (Petters and Kreidenweis, 2007) have been calculated at $90 \% \mathrm{RH}$ and at the critical point using the same case study displayed in Fig. 1, for 3 number concentrations of monodisperse $50 \mathrm{~nm}$ particles, 60,600 and $6000 \mathrm{~cm}^{-3}$. At the higher concentrations because the increase in condensable mass per particle is much reduced, the new $\kappa$-Köhler values resulting from co-condensation are almost identical from both the HTDMA and CCN. On the other hand, decreasing the number concentration by a factor of 10 increases the divergence in derived $\kappa$-Köhler values between both instruments. These results clearly indicate that the ability to reconcile behaviour in both instruments and the atmosphere is not only dependent on volatility profiles but also the number of particles.

The equilibrium can be considered as a limiting case that is approached asymptotically over time. In this sense, our simulations provide a upper bound on the impact of cocondensation of semi-volatiles on cloud activation. It is not possible to extend the consideration of impacts to cloud droplet number or radiative forcing using recently developed parameterisations such as that presented by Wang et al. (2008) since the particle size or apparent hygroscopicity will change throughout particle activation and the dependence of droplet number on particle size distribution does not have a unique relationship, but depends on the volatility of ambient vapours. The approach, as used by Topping et al. (2011), is therefore subject to these limitations. It is clear that the consideration of the movement towards equilibrium of all ambient semi-volatile components has the potential to be larger than any previous studied composition dependence of cloud droplet activation. Replicating the true atmospheric behaviour of aerosol particles poses challenges for both the modelling and measurement community, our simulations suggesting it is impossible to uncouple composition and size in studying the role of aerosol particles in radiative forcing, as once previously thought (Dusek et al., 2006). 


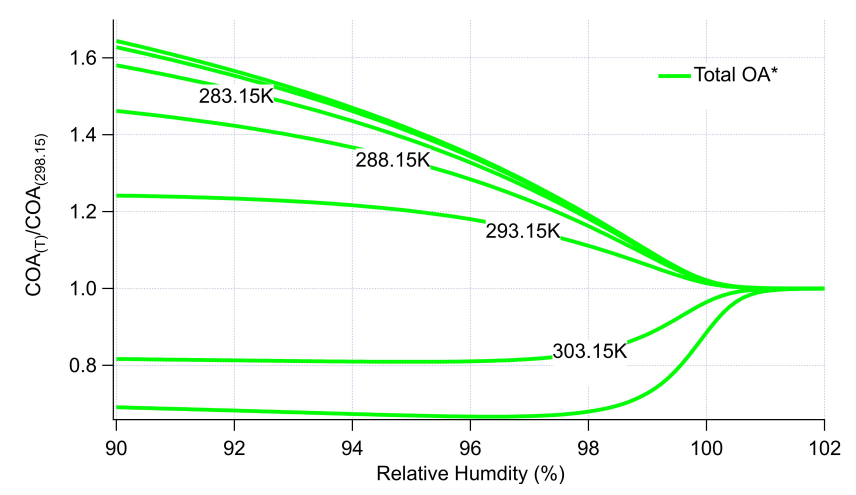

Fig. A1. Ratio of predicted condensed organic material at given temperature $\mathrm{COA}_{T} / \mathrm{COA}_{298.15}$ (annotated on each line) to that at $298.15 \mathrm{~K}$ as a function of RH. The "Total OA" semi volatile distribution described in the main body of text is used as an example.

\section{Appendix A}

Each condensing compound has an equivalent equation to the traditional Köhler equation, such that for component " $i$ " we have:

$S_{i}=a_{i} \exp \left(\frac{2 v_{i} \sigma_{\mathrm{ws}}}{R T r_{\mathrm{drop}}}\right)=P_{i} / P_{i \mathrm{o}}$

where $S_{i}$ is the saturation ratio of component $i, P_{i}$ the partial pressure of $i$ and $P_{i \mathrm{o}}$ the pure component vapour pressure of $i$. $P_{i \mathrm{o}}$ represents the the partial pressure of $i$ above a flat single component system comprising only itself in a sub-cooled state.

$v_{i}$ is the partial molar volume and $a_{i}$ the "activity" of component $i$. The activity is simply the mole fraction multiplied by a mole fraction-based activity coefficient $f_{i}$ which accounts for intermolecular interactions within solution. The model UNIFAC (Fredenslund et al., 1975) was used to account for non-ideality in the case of the simulations with the Master Chemical Mechanism (Jenkin et al., 1997). For the calculations including the volatility distributions of Cappa and Jimenez (2010) ideal mixing in the condensed phase is assumed, i.e. activity coefficients of unity.

Simultaneously solving this equation for each compound within an iterative method enables construction of a new Köhler curve, thus cloud activation predictions. The Master Chemical Mechanism (Jenkin et al., 1997) was used to predict the gas phase abundance of 2727 compounds for a test case in which the ratio of anthropogenic to biogenic VOC's to $\mathrm{NO}_{\mathrm{x}}$ was $1: 1: 1$. The pure component vapour pressures $P_{i \mathrm{o}}$ were calculated using the Nannoolal method (Nannoolal et al., 2008) as recommended by Barley and McFiggans (2010).

As there may be a noticeable impact of temperature on the predicted $S_{\text {crit }}$ the calculations were conducted at a range of temperatures with assumed enthalpy of vapourisation $\Delta H_{\mathrm{vap}}$ equal to $150 \mathrm{~kJ} \mathrm{~mol}^{-1}$. The predicted $S_{\text {crit }}$ does decrease slightly as the temperature decreases as a result of a drop in component volatility, with consequent increase in soluble mass. However, the relative difference in soluble mass tends toward zero as the RH approaches $100 \%$. Figure 1 shows the ratio of predicted condensed organic material at a given temperature to that at $298.15 \mathrm{~K}$, as a function of RH, using the "Total OA" (Oxygenated aerosol) volatility profile of Cappa and Jimenez (2010) described in the main body of text and displayed in Fig. A1. At $90 \%$ RH, a decrease in temperature of $15 \mathrm{~K}$ leads to a predicted increase in condensed organic mass by a factor of 1.6. At relative humidities approaching $100 \%$ however, all ratios converge to unity.

Acknowledgements. D. Topping was supported by UK National Centre for Atmospheric Sciences (NCAS) funding.

Edited by: C. Hoose

\section{References}

Albrecht, B. A.: Aerosols, Cloud Microphysics, and Fractional Cloudiness, Science, 245, 1227-1230, 1989.

Aumont, B., Szopa, S., and Madronich, S.: Modelling the evolution of organic carbon during its gas-phase tropospheric oxidation: development of an explicit model based on a self generating approach, Atmos. Chem. Phys., 5, 2497-2517, doi:10.5194/acp-52497-2005, 2005

Barley, M. H. and Mc Figgans, G.: The critical assessment of vapour pressure estimation methods for use in modelling the formation of atmospheric organic aerosol, Atmos. Chem. Phys., 10, 749-767, doi:10.5194/acp-10-749-2010, 2010.

Camredon, M., Hamilton, J. F., Alam, M. S., Wyche, K. P., Carr, T., White, I. R., Monks, P. S., Rickard, A. R., and Bloss, W. J.: Distribution of gaseous and particulate organic composition during dark $\alpha$-pinene ozonolysis, Atmos. Chem. Phys., 10, 2893-2917, doi:10.5194/acp-10-2893-2010, 2010.

Cappa, C. D. and Jimenez, J. L.: Quantitative estimates of the volatility of ambient organic aerosol, Atmos. Chem. Phys., 10, 5409-5424, doi:10.5194/acp-10-5409-2010, 2010.

Donahue, N. M., Epstein, S. A., Pandis, S. N., and Robinson, A. L.: A two-dimensional volatility basis set: 1. organic-aerosol mixing thermodynamics, Atmos. Chem. Phys., 11, 3303-3318, doi:10.5194/acp-11-3303-2011, 2011.

Duplissy, J., DeCarlo, P. F., Dommen, J., Alfarra, M. R., Metzger, A., Barmpadimos, I., Prevot, A. S. H., Weingartner, E., Tritscher, T., Gysel, M., Aiken, A. C., Jimenez, J. L., Canagaratna, M. R., Worsnop, D. R., Collins, D. R., Tomlinson, J., and Baltensperger, U.: Relating hygroscopicity and composition of organic aerosol particulate matter, Atmos. Chem. Phys., 11, 1155-1165, doi:10.5194/acp-11-1155-2011, 2011.

Dusek, U., Frank, G. P., Hildebrandt, L., Curtius, J., Schneider, J., Walter, S., Chand, D., Drewnick, F., Hings, S., Jung, D., Borrmann, S., and Andreae, M. O.: Size matters more than chemistry for cloud-nucleating ability of aerosol particles, Science, 312, 1375-1378, 2006.

Ekström, S., Nozière, B., Hultberg, M., Alsberg, T., Magnér, J., Nilsson, E. D., and Artaxo, P.: A possible role of ground-based 
microorganisms on cloud formation in the atmosphere, Biogeosciences, 7, 387-394, doi:10.5194/bg-7-387-2010, 2010.

Facchini, M. C., Mircea, M., Fuzzi, S. and Charlson, R. J.: Cloud albedo enhancement by surface-active organic solutes in growing droplets, Nature, 401, 257-259, 1999.

Fredenslund, A., Jones, R. L., and Prausnitz, J. M.: GroupContribution Estimation of Activity-Coefficients in Nonideal Liquid-Mixtures, Aiche J., 21, 1086-1099, 1975.

Goldstein, A. H. and Galbally, I. E.: Known and unexplored organic constituents in the earth's atmosphere, Environ. Sci. Technol., 41, 1514-1521, 2007.

Good, N., Topping, D. O., Duplissy, J., Gysel, M., Meyer, N. K., Metzger, A., Turner, S. F., Baltensperger, U., Ristovski, Z., Weingartner, E., Coe, H., and McFiggans, G.: Widening the gap between measurement and modelling of secondary organic aerosol properties?, Atmos. Chem. Phys., 10, 2577-2593, doi:10.5194/acp-10-2577-2010, 2010.

Gysel, M., Weingartner, E., Nyeki, S., Paulsen, D., Baltensperger, U., Galambos, I., and Kiss, G.: Hygroscopic properties of water-soluble matter and humic-like organics in atmospheric fine aerosol, Atmos. Chem. Phys., 4, 35-50, doi:10.5194/acp-4-352004, 2004.

Hallquist, M., Wenger, J. C., Baltensperger, U., Rudich, Y., Simpson, D., Claeys, M., Dommen, J., Donahue, N. M., George, C., Goldstein, A. H., Hamilton, J. F., Herrmann, H., Hoffmann, T., Iinuma, Y., Jang, M., Jenkin, M. E., Jimenez, J. L., Kiendler-Scharr, A., Maenhaut, W., McFiggans, G., Mentel, Th. F., Monod, A., Prévôt, A. S. H., Seinfeld, J. H., Surratt, J. D., Szmigielski, R., and Wildt, J.: The formation, properties and impact of secondary organic aerosol: current and emerging issues, Atmos. Chem. Phys., 9, 5155-5236, doi:10.5194/acp-95155-2009, 2009.

Irwin, M., Good, N., Crosier, J., Choularton, T. W., and McFiggans, G.: Reconciliation of measurements of hygroscopic growth and critical supersaturation of aerosol particles in central Germany, Atmos. Chem. Phys., 10, 11737-11752, doi:10.5194/acp10-11737-2010, 2010.

Jenkin, M. E., Saunders, S. M., and Pilling, M. J.: The tropospheric degradation of volatile organic compounds: a protocol for mechanism development, Atmos. Environ., 31, 81-104, 1997.

Jimenez, J. L., Canagaratna, M. R., Donahue, N. M., Prevot, A. S. H., Zhang, Q., Kroll, J. H., Decarlo, P. F., Allan, J. D., Coe, H., Ng, N. L., Aiken, A. C., Docherty, K. S., Ulbrich, I. M., Grieshop, A. P., Robinson, A. L., Duplissy, J., Smith, J. D., Wilson, K. R., Lanz, V. A., Hueglin, C., Sun, Y. L., Tian, J., Laaksonen, A., Raatikainen, T., Rautiainen, J., Vaattovaara, P., Ehn, M., Kulmala, M., Tomlinson, J. M., Collins, D. R., Cubison, M. J., Dunlea, E. J., Huffman, J. A., Onasch, T. B., Alfarra, M. R., Williams, P. I., Bower, K., Kondo, Y., Schneider, J., Drewnick, F., Borrmann, S., Weimer, S., Demerjian, K., Salcedo, D., Cottrell, L., Griffin, R., Takami, A., Miyoshi, T., Hatakeyama, S., Shimono, A., Sun, J. Y., Zhang, Y. M., Dzepina, K., Kimmel, J. R., Sueper, D., Jayne, J. T., Herndon, S. C., Trimborn, A. M., Williams, L. R., Wood, E. C., Middlebrook, A. M., Kolb, C. E., Baltensperger, U., and Worsnop, D. R.: Evolution of organic aerosols in the atmosphere, Science, 326, 1525-1529, doi:10.1126/science.1180353, 2009.

Köhler, H.: The nucleus in and the growth of hygroscopic droplets, T. Faraday. Soc., 43, 1152-1161, 1936.
Kokkola, H., Romakkaniemi, S., and Laaksonen, A.: Köhler theory for a polydisperse droplet population in the presence of a soluble trace gas, and an application to stratospheric STS droplet growth, Atmos. Chem. Phys., 3, 2139-2146, doi:10.5194/acp-32139-2003, 2003

Kulmala, M., Laaksonen, A., Korhonen, P., Vesala, T., Ahonen, T., and Barrett, J. C.: The effect of atmospheric nitric acid vapor on cloud condensation nucleus activation, J. Geophys. Res., 98, 22949-22958, 1993.

Laaksonen, A., Korhonen, P., Kulmala, M. and Charlson, R. J.: Modification of the Kuhler equation to include soluble trace gases and slightly soluble substances, J. Atmos. Sci., 55, 853$862,1998$.

McFiggans, G., Artaxo, P., Baltensperger, U., Coe, H., Facchini, M. C., Feingold, G., Fuzzi, S., Gysel, M., Laaksonen, A., Lohmann, U., Mentel, T. F., Murphy, D. M., O’Dowd, C. D., Snider, J. R., and Weingartner, E.: The effect of physical and chemical aerosol properties on warm cloud droplet activation, Atmos. Chem. Phys., 6, 2593-2649, doi:10.5194/acp-6-2593-2006, 2006.

Nannoolal, Y., Rarey, J., and Ramjugernath, D.: Estimation of pure component properties, Part 3. Estimation of the vapor pressure of non-electrolyte organic compounds via group contributions and group interactions, Fluid Phase Equilibr., 269, 117-133, 2008.

Pankow, J. F.: An absorption model of gas/particle partitioning in the atmosphere, Atmos. Environ., 28, 185-188, 1994.

Petters, M. D. and Kreidenweis, S. M.: A single parameter representation of hygroscopic growth and cloud condensation nucleus activity, Atmos. Chem. Phys., 7, 1961-1971, doi:10.5194/acp-71961-2007, 2007.

Roberts, G. C. and Nenes, A.: A continuous-flow streamwise thermal-gradient $\mathrm{CCN}$ chamber for atmospheric measurements, Aerosol Sci. Technol., 39, 206-221, 360, 361, 362, 206-221, 2005.

Romakkaniemi, S., Kokkola, H., and Laaksonen, A.: Soluble trace gas effect on cloud condensation nuclei activation: Influence of initial equilibration on cloud model results, J. Geophys. Res., 110, D15202, doi:10.1029/2004JD005364, 2005.

Shulman, M. L., Jacobson, M. C., Charlson, R. J., Synovec, R. E., and Young, T. E.: Dissolution behavior and surface tension effects of organic compounds in nucleating cloud droplets, Geophys. Res. Lett., 23, 277-280, 1996.

Solomon, S., Qin, D., Manning, M., Chen, Z., Marquis, M., Averyt, K. B., Tignor, M., and Miller, H. L. (Eds.).: Contribution of Working Group I to the Fourth Assessment Report of the Intergovernmental Panel on Climate Change, 2007.

Sorjamaa, R., Svenningsson, B., Raatikainen, T., Henning, S., Bilde, M., and Laaksonen, A.: The role of surfactants in Köhler theory reconsidered, Atmos. Chem. Phys., 4, 2107-2117, doi:10.5194/acp-4-2107-2004, 2004

Swietlicki, E., Hansson, H. C., Hameri, K., Svenningsson, B., Massling, A., McFiggans, G., McMurry, P. H., Petaja, T., Tunved, P., Gysel, M., Topping, D., Weingartner, E., Baltensperger, U., Rissler, J., Wiedensohler, A., and Kulmala, M.: Hygroscopic properties of submicrometer atmospheric aerosol particles measured with H-TDMA instruments in various environments a review, Tellus B, 60, 432-469, 2008.

Tong, H.-J., Reid, J. P., Bones, D. L., Luo, B. P., and Krieger, U. K.: Measurements of the timescales for the mass transfer of water in 
glassy aerosol at low relative humidity and ambient temperature, Atmos. Chem. Phys., 11, 4739-4754, doi:10.5194/acp-11-47392011, 2011.

Topping, D. O., Barley, M. H., and McFiggans, G.: The sensitivity of Secondary Organic Aerosol component partitioning to the predictions of component properties - Part 2: Determination of particle hygroscopicity and its dependence on "apparent" volatility, Atmos. Chem. Phys., 11, 7767-7779, doi:10.5194/acp-11-77672011, 2011.

Twomey, S.: The influence of pollution on the shortwave albedo of clouds, J. Atmos. Sci., 34, 1149-1152, 1977.

Virtanen, A., Joutsensaari, J., Koop, T., Kannosto, J., Yli-Pirila, P., Leskinen, J., Makela, J. M., Holopainen, J. K., Pöschl, U., Kulmala, M., Worsnop, D. R., and Laaksonen, A.: An amorphous solid state of biogenic secondary organic aerosol particles, Nature, 467, 824-827, 2010.
Wang, J., Lee, Y.-N., Daum, P. H., Jayne, J., and Alexander, M. L.: Effects of aerosol organics on cloud condensation nucleus $(\mathrm{CCN})$ concentration and first indirect aerosol effect, Atmos. Chem. Phys., 8, 6325-6339, doi:10.5194/acp-8-6325-2008, 2008.

Warner, J.: A reduction in rainfall with smoke from sugar-cane fires an inadvertent weather modification?, J. Appl. Meteorol., 7, 247251, 1968.

Wex, H., Petters, M. D., Carrico, C. M., Hallbauer, E., Massling, A., McMeeking, G. R., Poulain, L., Wu, Z., Kreidenweis, S. M., and Stratmann, F.: Towards closing the gap between hygroscopic growth and activation for secondary organic aerosol: Part 1 Evidence from measurements, Atmos. Chem. Phys., 9, 39873997, doi:10.5194/acp-9-3987-2009, 2009. 